\title{
Rehabilitación de la plaza público patrimonial "La Aguilita" en el Centro Histórico de la Ciudad de México por medio de la participación ciudadana.
}

\author{
María Guadalupe Valiñas Varela \\ Escuela Superior de Ingeniería y Arquitectura ESIA Tecamachalco, \\ Instituto Politécnico Nacional. Ciudad de México, México \\ E-mail: arquinova@hotmail.com
}

\begin{abstract}
Resumen. Plaza Aguilita también denominada "Plaza Juan José Baz" es una de las plazas público patrimoniales de mayor importancia en la historia de los símbolos patrios de la Nación en México, pues se dice que el águila que encontraron los mexicas se posó en este lugar, ubicado en la Merced. Actualmente dicho lugar, es un espacio publico de conflicto, con diversas problemáticas sociales, sin embargo, por medio de brigadas multidisciplinarias de alumnos del Instituto Politécnico Nacional, se ha trabajado con los vecinos para devolver esa identidad comunitaria y su magnificencia, por tratarse de un espacio que se ha caracterizado por identificarse a través de la memoria histórica de los habitantes como un lugar sagrado donde se dio el suceso que reflejó el origen de todo un pueblo y de sus tradiciones. Empero, el paisaje urbano aledaño presenta diversas zonas de deterioro en edificios patrimoniales históricos, además una imagen urbana desorganizada que no corresponde al simbolismo del lugar. La Autoridad del Centro Histórico trabaja con alumnos del IPN y vecinos para incluir el proyecto de rehabilitación de la misma en el Programa de mejoramiento barrial del Centro Histórico de la Ciudad de México. Un lugar emblemático por su historia y trascendencia que actualmente organiza es punto importante de la centralidad en la ciudad.
\end{abstract}

Palabras clave: imagen urbana, participación ciudadana, espacio público patrimonial, turistificación y gentrificación.

\section{Introducción: Importancia de la Rehabilitación de plazas público patrimoniales en el CH de la CDMX}

En la actualidad, el Urbanismo está transformándose, al mirar proyectos $\mathrm{y}$ propuestas urbano arquitectónicas de distinta manera, toda vez, que el rechazo y la resistencia, así como la falta de aprobación de los habitantes, representa un punto importante a considerar en las intervenciones actuales, pues es indispensable que estos sean considerados como parte de los mismos, a efecto de generar esa inclusión tanto local como glocal fomentando el turismo, de tal forma, que se conozcan estos espacios públicos de manera generalizada junto con su historia y su valor; lo anterior se pudo realizar en el Proyecto denominado "La Técnica al Servicio del Corazón de la Patria", eslogan que es característico del Instituto Politécnico Nacional sin la palabra corazón, misma que refiere al Centro Histórico como corazón de nuestro país. El proyecto consiste en la rehabilitación de las siguientes cuatro plazas público patrimoniales: la plaza de Loreto, la plaza de la Concepción, la plaza de la Santísima, así como la que nos refiere el presente trabajo, "La plaza de la Aguilita”. Dicho proyecto comenzó en septiembre 2018 y se extendió con un proyecto de investigación a la par en el IPN que se encuentra activo desde principios de enero del 
2019 el cual concluye en enero del 2020 donde se contemplará la posible rehabilitación de plazas en el perímetro A del Centro Histórico, las cuales se encuentren en malas condiciones y presenten diversas problemáticas sociales.

Se plantea el siguiente problema, entornos deteriorados del espacio público, al máximo, reflejando una pobreza extrema en sus alrededores, y con problemas latentes de turistificación y gentrificación, ante las posibles intervenciones por parte del gobierno, es común el rechazo de comunidades, ciudadanos $\mathrm{y}$ actores, ante esa perspectiva se plantean una serie de cuestionamientos para obtener propuestas de solución al problema.

El supuesto hipotético parte de que al generar nuevos procesos urbanos basados en la participación ciudadana y colaborativa se puede combatir la gentrificación y la turistificación en el espacio público patrimonial, así como su deterioro y mejorar la imagen urbana y paisajística del sitio, a partir de la revalorización del mismo con propuestas incluyentes hacia los vecinos que valoren y cuiden ese espacio.

Las ciudades se reinscriben sobre si mismas como si se tratara de un palimpsesto, pero la memoria histórica está presente y debe ser considerada para preservar estos espacios dignamente en las intervenciones y que éstas logren espacios dignos para ser compartidos tanto a mexicanos como a extranjeros, pero con una conciencia de valor patrimonial.

Françoise Choay nos muestra un debate de los urbanistas en dos vertientes: los culturalistas y los progresistas; los primeros en aras de preservar el patrimonio histórico y salvaguardarlo de la mano con tradiciones y costumbres y los segundos, preocupados por la innovación, la regeneración y el desarrollo. Se trata de encontrar un equilibrio entre ambas corrientes con la finalidad de que se conserve nuestra identidad en el espacio público patrimonial.

El objetivo principal es evaluar los procesos urbanos que se gestan en torno a la preservación del Patrimonio del espacio público existente en el caso de las plazas, para definir el camino correcto de su intervención por medio de la participación ciudadana.

Los objetivos secundarios, son la recaudación de datos e información tanto cuantitativa como cualitativa y su análisis en la Merced y en el entorno de Plaza Aguilita a fin de dar luz para la posible rehabilitación de la plaza.

La justificación del tema se fundamenta en el valor de estas plazas desde tiempos de la cultura mexica, al ser Plaza Aguilita una de las más representativas por su historia reflejada en la memoria colectiva que la identifica como el lugar original donde se encontró el águila posada en el nopal.

Por lo anterior es imprescindible manejar metodologías estructuradas en métodos que sustenten desde un enfoque complejo lo observado, sin ver de forma específica un problema, sino considerando todo su alrededor $\mathrm{y}$ atendiendo de forma vertical, de abajo hacia arriba las problemáticas, desde los intereses de los ciudadanos y no del poder económicopolítico y en un camino de doble vía, de lo general a lo particular y viceversa, así como de forma recursiva.

La hermenéutica profunda vislumbra a través del análisis de textos obtenidos en el estudio de campo, respuesta a las incógnitas generadas a lo largo de ésta investigación.

¿Quién debe ser partícipe del espacio público patrimonial, los habitantes, los extranjeros, los gobernantes, los ciudadanos, o los turistas?

¿Cómo deben ser los proyectos urbanos de Arquitectura del Paisaje en el espacio público patrimonial?

¿Cuándo es pertinente y viable un proyecto para rehabilitar estas plazas?

¿Qué papel juega el Patrimonio histórico y artístico en los espacios públicos?

Lo anterior refleja una serie de cuestionamientos que parten de las palabras "quién, cómo, cuándo, dónde y para qué" y las respuestas dan lugar a ver el Diseño Urbano Arquitectónico de otra manera en esa aplicación colectiva de la Arquitectura del Paisaje

Por lo anterior éste documento maneja el siguiente contenido tratando los diversos temas de forma objetiva, de tal suerte, que no se manejen estos temas como algo político sino educativo donde se tenga como prioridad la meta de mejorar la calidad de vida, el bienestar en el habitar diario y futuro de los espacios público patrimoniales y preservar el Patrimonio Histórico de alrededor.

El contenido se desarrolla en cinco 


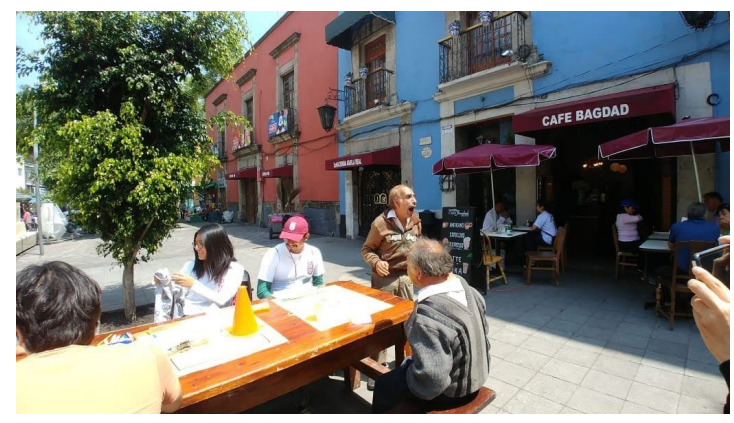

Fig. 1. Trabajo de alumnos del servicio social en plaza Aguilita. (Fuente: Archivo personal Noviembre 2018)

apartados que tratan los siguientes tópicos, el apartado 1 refiere el marco histórico, como fue la llegada de Aztlán de clanes que conformaron Tenochtitlán y la historia de la tierra prometida.

El apartado 2 refiere el marco teórico, define la turistificación, la gentrificación, así como los procesos urbanos actuales relacionados con el espacio público patrimonial en la ciudad compacta versus ciudad difusa y su relación con la exclusión y el consumo.

El apartado 3 aborda la metodología desde un enfoque complejo y hermenéutico a partir de diversos instrumentos analizados de forma cualitativa y cuantitativa.

El apartado 4 menciona los hallazgos y la propuesta conceptual lograda de forma colaborativa entre alumnos del servicio social, profesores y vecinos de Plaza Aguilita.

El apartado 5 contempla las conclusiones y el estado del proyecto, y la tendencia de nuevas formas para ver el proyecto urbano en el espacio público.

\section{Marco Histórico. El imperio de Tenochtitlán y la Merced.}

Los mexicas fundaron la antigua Tenochtitlan sobre terreno lacustre, se asentaron en ésta zona, pues se dice que observaron un símbolo que les indicó que habían llegado al lugar prometido, ese símbolo fue el águila y la serpiente. Se dice de manera coloquial entre los habitantes que el lugar real donde esto ocurrió fue en lo que es hoy la plaza Aguilita, que hace honor a su historia con una fuente con una escultura representativa que fue donada por Casa Talavera perteneciente a la UACM.

La ubicación de esta plaza está inmersa de historia, así lo refiere Sanz en el siguiente apartado:

La historia del Centro Histórico de la ciudad de México referido a Tenochtitlán y el ombligo de la luna es el lugar fundacional de las megalópolis más grandes del planeta, cuya sede, el Valle de México, es un territorio

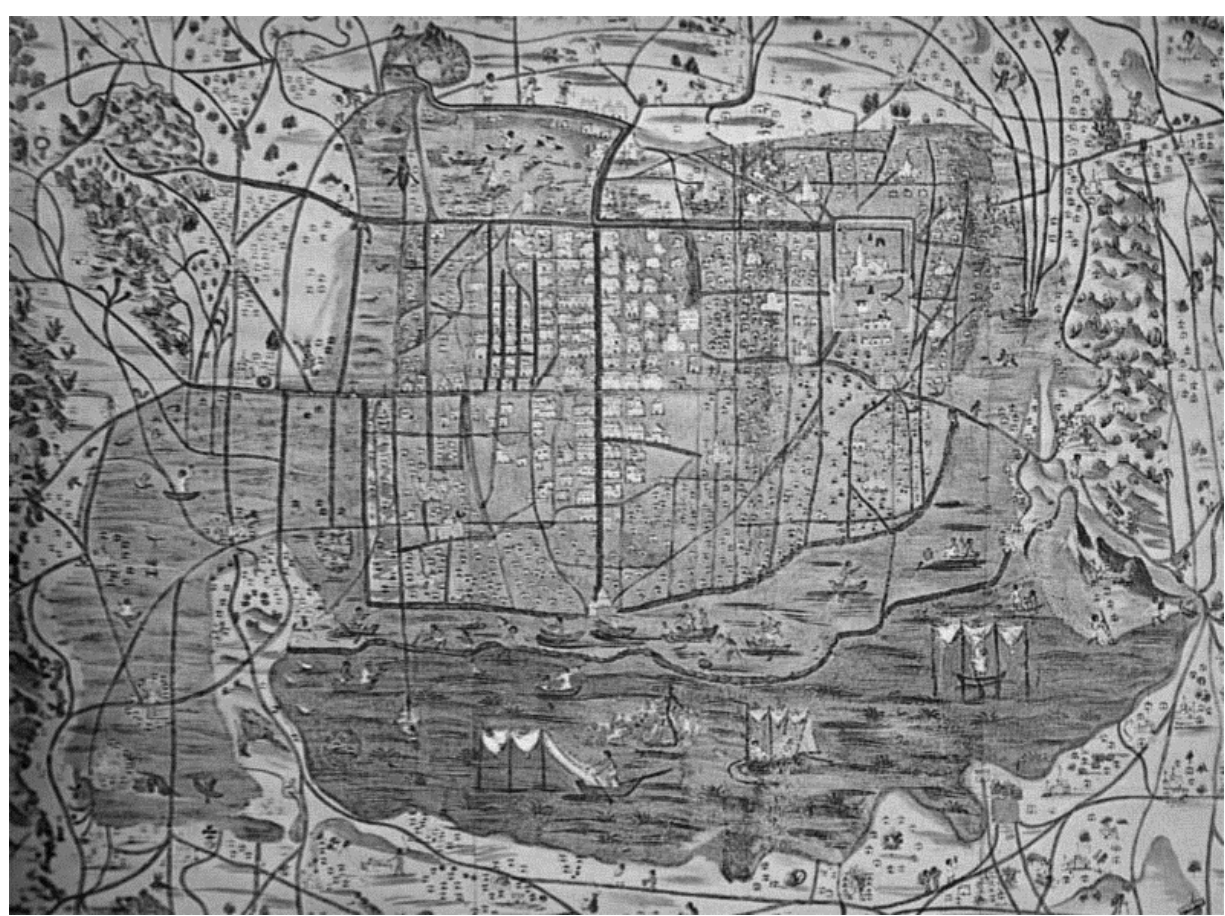

Fig. 2. Plano representando a la Ciudad de México Tenochtitlán alrededor de $1550 .{ }^{1}$ 
de aproximadamente $9600 \mathrm{~km} 2$ que durante miles de años albergó un sistema extenso de cuerpos de agua, compuesto por el gran lago de Texcoco y por los lagos menores de Xochimilco y Chalco. (Sanz, 2018:39)

La antigua Tenochtitlán se fundó con cuatro cuadrantes básicos, Moyotlan, Cuepopan, Atzacoalco, y Teopan. La Merced, es uno de los barrios más antiguos del Centro Histórico y pertenece a este último; no hay una fecha exacta de su fundación, pero se dice que fue entre 1312 y 1321. La Merced se remonta a principios de la colonia, siempre tuvo la característica de contar con el mercado ambulante. En los ochentas la Merced se había convertido en el mercado de abastos más popular de la Ciudad de México.

La plaza que abordamos en éste trabajo está ubicada en la Merced y el 20 de marzo 1868 recibió el nombre de Juan José Baz quien Gobernó el Distrito Federal de 1855 a 1856, en la época de la Reforma (Lozada, 1991:54), quien se caracterizó por sus ideas liberales e intentó destruir la Catedral Metropolitana, cosa que no logró.

La Plaza también es conocida como "La Aguilita", porque se dice que ahí se encontró la famosa águila devorando la serpiente y parada sobre el nopal que dio inició al gran imperio Tenoch. Este espacio tiene en el centro de la plaza una fuente con una escultura de un águila pequeña la cual dio nombre al lugar.

La historiadora y cronista de la Ciudad de México, Ángeles González Gamio (citado en Olivares E., 2017), también considera que ese lugar de origen pudo ser la zona que hoy ocupa la Plaza Juan José Baz, debido a dos razones muy importantes: "Una, es que éste era el barrio conocido como de los temazcales, que estaban aquí porque había muchos manantiales. Cerca de la zona se ubicaron unos baños que fueron muy famosos durante muchos siglos: los Baños del Montón. Y otra cuestión, es que (La Merced) era conocida como el barrio de Teopan, cuyo nombre significa "lugar de los dioses" o "lugar donde se venera lo más sagrado".

La leyenda cuenta que Huitzilopochtli abandona a su hermana Malinalxochitl en Malinalco, debido a que ésta aterrorizaba a los mexicas. Despechada por el abandono,
Malinalxochitl tiene un hijo, Copil, quien crece alimentado por el rencor de la madre hacia su tío y en la primera oportunidad lo ataca. Aquí las versiones se dividen, pues mientras que unos sostienen que el sobrino sorprendió a su tío en el cerro de Chapultepec, otros aseguran que la lucha se lleva a cabo en el cerro Tepetzinco, hoy Peñón de los Baños. "Ahí, en el cerro, Huitzilopochtli derrota a Copil y le saca el corazón (...) El belicoso dios lanza el corazón de su sobrino con tal fuerza que parece un cometa surcando el cielo y luego cae en algún lugar del lago". En ese punto geográfico es donde ocurrirá la aparición.

El corazón de Copil cayó en el mismo punto donde se libró la batalla contra Huitzilopochtli: en el Peñón de los Baños. "La sangre de Copil según la leyenda- les dio a las aguas de la zona una temperatura especial. Asimismo, El Peñón, emparentado estrechamente con los símbolos patrios, vio cómo a lo largo de los siglos creció la civilización y los nuevos habitantes de esta zona se apropiaron del entorno natural". Al respecto el escritor Armando Ramírez (citado Olivares E., 2017) asegura que en el punto donde se libró la batalla de los dioses, "hay actualmente una capilla construida sobre vestigios prehispánicos".

En la actualidad el gobierno capitalino colocó 42 piezas de talavera con todos los escudos nacionales que se han usado en la historia. Al centro, se encuentra una fuente adornada con una columna de piedra donde la imagen del águila con la serpiente en el pico

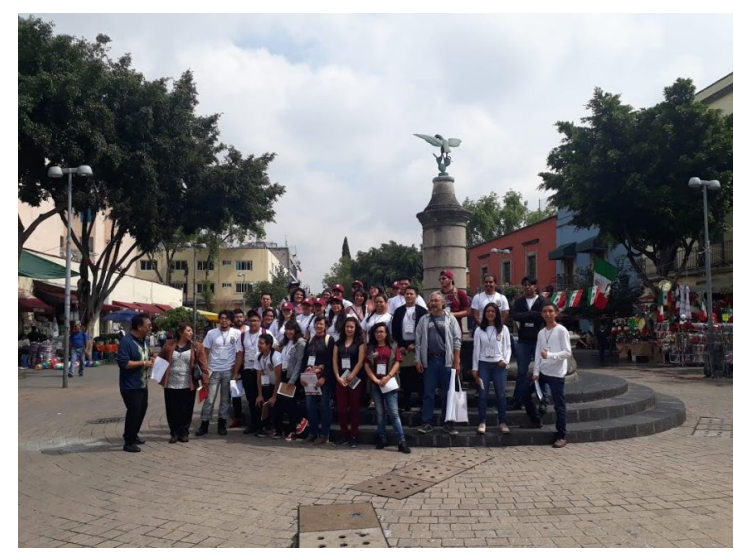

Fig. 3. Fuente con la aguilita de la plaza ${ }^{2}$, representativa de la leyenda del lugar y alumnos de las brigadas del servicio social para el Proyecto "la Técnica al Servicio del Corazón de la Patria". 
corona y domina la vista de todos los puntos de la explanada (Olivares E., 2017).

Plaza Aguilita pertenece a la Merced que desde tiempos de la Conquista se caracterizaba por ser un lugar de comercio de alimentos, al principio en la Nueva España, se convirtió en una zona residencial, pero con el tiempo esto cambió como se observa en la siguiente cita:

Sin embargo, esta aristocracia de un barrio humilde "como le han llamado algunos autores, fue cediendo el espacio de sus casas habitación para la creación de viviendas populares, vecindades, bodegas y comercios de diversos rubros durante las siguientes décadas. Resulta complejo analizar cuál es el verdadero origen de las vecindades en la zona, aunque se afirma que un gran sector de la Merced pertenecía a principio de siglo a una parte integrante de los barrios bajos en un sector de la ciudad considerado decadente y con partes de habitaciones correspondientes a la Herradura de Tugurios" (Castillo, 2015:51)

La condición actual es contrastante, así se observa:

En este escenario considerado de riqueza histórica, social y económica, también se observa con gran preocupación e incertidumbre, el impacto que tienen las fuerzas hegemónicas que naturalizan la pobreza, el desempleo, el deterioro ambiental y la miserabilización de la cultura, haciendo de los indígenas, de los niños pepenadores y de las mujeres.....desechos, condición impuesta por una estructura de poder que ha demostrado ser injusta, incapaz y depredadora, que antepone los intereses de lucro, auspicia la corrupción y expulsa cotidianamente a los habitantes del barrio (Tena, 2009:35)

Al pertenecer Plaza Aguilita al Barrio de la Merced conserva las características del mismo, donde la falta de equidad, el comercio ambulante desregulado, el deterioro, entre otros son característicos también de la Plaza.

\section{Marco Teórico. La globalización produce Turistificación y gentrificación, relación con el Urbanismo y la Arquitectura del Paisaje.}

La época actual está inmersa en la globalización, a la cual algunos autores relacionan con lo líquido y con la característica de que se

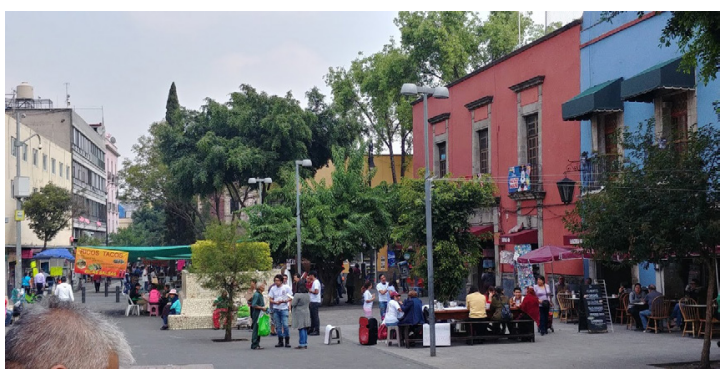

Fig. 4. Trabajos en la Plaza Aguilita, se observa turismo, consumo, y deterioro. (Fuente: Archivo personal septiembre 2018)

desvanece con rapidez, las cosas cambian fácilmente de modo, el consumo prevalece y es fácil desplazarse de un lugar a otro por todo el mundo.

La nueva "plenitud del planeta" el alcance global de los mercados (financiero, laboral y de bienes de consumo) de la modernización gestionada por el capital y por ende, del modo de vida moderno- tiene dos consecuencias directas: la obstrucción de los desagües que en el pasado permitían drenar y limpiar a tiempo y con regularidad, los relativamente escasos enclaves modernos del planeta de sus excedentes humanos que la forma de vida moderna sólo podía producir en proporción creciente: la población superflua, supernumeraria y excesiva. (Bauman, 2012:46)

La gentrificación y la turistificación están ampliamente ligadas con ese fácil desplazamiento global, hoy al usar el internet es fácil conocer un espacio o un lugar sin la necesidad de estar ahí; la oferta y la demanda ocupan un lugar importante en este tema, pues los que tienen el mayor poder adquisitivo están dentro y los que carecen de recursos no tienen derecho a la ciudad y están fuera, ocupando generalmente las periferias mientras el espacio central está en constante disputa. La gentrificación trata de esa relación con el desplazamiento de los habitantes originarios por gente nueva que llega al lugar con mayores recursos económicos que transforman la tipología de los inmuebles. La turistificación es el desequilibrio total del turismo, donde los habitantes son perjudicados por grandes masas que se desplazan y en muchas ocasiones dañan el patrimonio con la intención de conocer lugares interesantes que son invadidos de manera masiva por los turistas. 
En cuanto a la relación oferta-demanda con la gentrificación Ley sostiene en 1980: que el cambio de habitantes de la zona central se produce debido a la existencia de agentes con una nueva ideología liberal proveniente del fortalecimiento del sector de servicios en la economía de las ciudades, donde la alta calificación, estatus y nivel profesional se da con una demanda de espacios en el centro de la ciudad, con el fin de llevar a cabo una "vida urbana" que promueve elementos culturales ligados al hedonismo ${ }^{3}$ (Vergara 2013:223)

Este hedonismo, sin lugar a dudas, está relacionado con esa nueva forma de ver la vida, de desechar las cosas con facilidad y rapidez como lo refiere Bauman en el 2012 en su estudio que relaciona con tiempos líquidos.

En muchos casos de manera intencionada se devalúan las zonas para ser posteriormente vendidas al mejor postor en un precio más alto.

El proceso anterior también es explicado por Neil Smith, quien desestima las teorías provenientes de la demanda y refuerza las de la oferta con la teoría de "the rent gap" o "brecha de renta", donde se contempla un diferencial en la renta actual capitalizada y la renta futura que se puede lograr; es decir, el potencial de beneficio que se genera para los desarrolladores inmobiliarios en donde éstos pretenden devaluar al máximo la renta actual capitalizada y apreciar en un futuro la máxima renta potencial (López Morales, 2009).

El caso del Centro Histórico de la Ciudad de México refiere un suelo en disputa por la fuerte cantidad de negocio que se realiza y las grandes cantidades de dinero que se mueven y su relación directa con el turismo.

En el presente trabajo se plantea la relación entre turismo y gentrificación, es decir, se analiza cómo el turismo de masas expulsa a la población local. Para las élites económicas la ciudad es un espacio del cual se pueden obtener beneficios, función que contrasta con las necesidades de vecinos y vecinas que entienden la ciudad como un espacio de residencia. (Cocola) ${ }^{4}$

En la actualidad el término de gentrificación goza de cierta popularidad dentro y fuera de los estudios urbanos, sin embargo, es un concepto que cuenta con casi medio siglo de existencia. La socióloga Glass (1964) utilizó por primera ocasión el término para referirse al proceso mediante el cual algunos barrios obreros de Londres experimentaron una revalorización a raíz de la compra y remodelación de casas victorianas por parte de sectores de clase media, generando un desplazamiento de los inquilinos de clase proletaria. (Hernández 2010:33)

No se puede decir que la gentrificación en México en nuestros días sea igual pero si se puede decir que el Centro Histórico de la Ciudad de México representa fuertes intereses económicos y una fuerte disputa por el suelo, donde variados casos de despojo se dan continuamente hacia los que menos tienen y en muchos casos son vecinos de la Merced, habitantes y locatarios, es por eso la responsabilidad de las instituciones académicas ante estos casos de injusticia y desigualdad social donde el patrimonio y los habitantes no son los que rigen los proyectos urbanos sino el neoliberalismo vigente.

"La responsabilidad de los intelectuales parte de una opción moral: combatir la injusticia, los privilegios y las exclusiones y la degradación del mundo". (Montaner 2017:11)

Esta responsabilidad intelectual, Jordi Borja, la aborda desde tres tipos de ejercicio: a) desarrollar una actividad crítica permanente, b) utilizar sus conocimientos para entender y explicar los mecanismos y las contradicciones que generan dichas dinámicas y participar en las reacciones sociales de los que se oponen a estas, c) contribuir a la elaboración de propuestas reformadoras de los mecanismos perversos y generar así culturas alternativas (Montaner 2017:12)

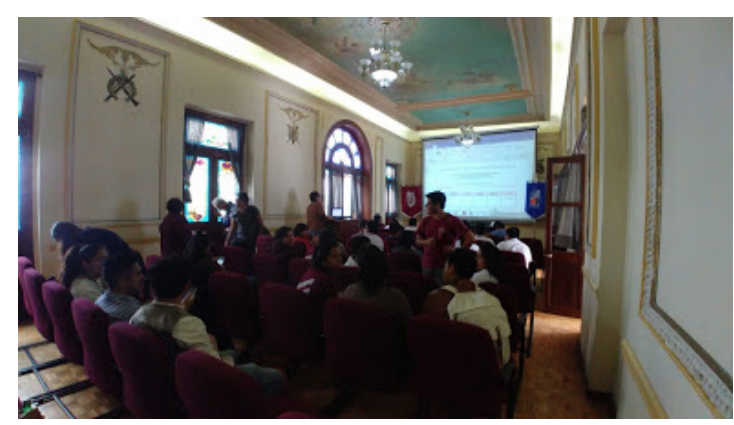

Fig. 5. Concientización del espacio público patrimonial a los alumnos del servicio social de las brigadas en el Proyecto "La Técnica al Servicio del Corazón de la Patria". (Fuente: Archivo personal septiembre 2018) 


\section{Metodología: El pensamiento complejo y la participación ciudadana}

La metodología está basada en el enfoque del pensamiento complejo como contenedor y base de análisis.

El pensamiento complejo nos permite ligar una extensa gama de planteamientos, siempre y cuando haya una relación coherente entre los mismos, formando como lo dice Edgar Morín un tejido complexus del todo.

El pensamiento complejo puede tener dos enfoques:

Interdisciplinario: Una forma de organización de los conocimientos en donde los métodos que han sido usados con éxito en una disciplina, se transfieren a otra.

Multidisciplinario: Una forma de organización de los conocimientos en donde se juntan varias disciplinas para que cada una proyecte una visión específica sobre un campo determinado. (Laguna 2016: XXI)

El proyecto parte de trabajar con la gente para que brigadas multidisciplinarias que realizan su servicio social, de las carreras de Turismo, Arquitectura, Topografía y Psicología, diagnostiquen las mismas y con trabajo de campo con los habitantes hagan propuestas de acuerdo a su expertise, de tal suerte, que se puedan lograr proyectos en el espacio público patrimonial que los habitantes sientan propios para su disfrute y bienestar social, fomentando la vida comunitaria, recuperando la identidad cultural y la memoria histórica. El proyecto es propuesto por el Dr. Jesús Porfirio González Schmal, quien fuera director de la Autoridad del Centro Histórico y coordinado por la Lic. Rosa Isela Martínez Martínez, conjuntamente con el taller de ciudad y cultura coordinado por el Dr. Tena, es una apuesta a trabajar de manera diferente en proyectos de Urbanismo y Arquitectura, en donde los proyectos no sean por imposición del Gobierno o por el interés de unos cuantos, sino en beneficio de la sociedad y en colaboración con ella.

La brigada multidisciplinaria está conformada de la siguiente manera:

Coordinador Brigada Multidisciplinaria y Apoyos: 01, Dra. Guadalupe Valiñas, Dr. José Antonio García Ayala, Mtro. Gregorio Luna (especialidad Arquitectura y Urbanismo),

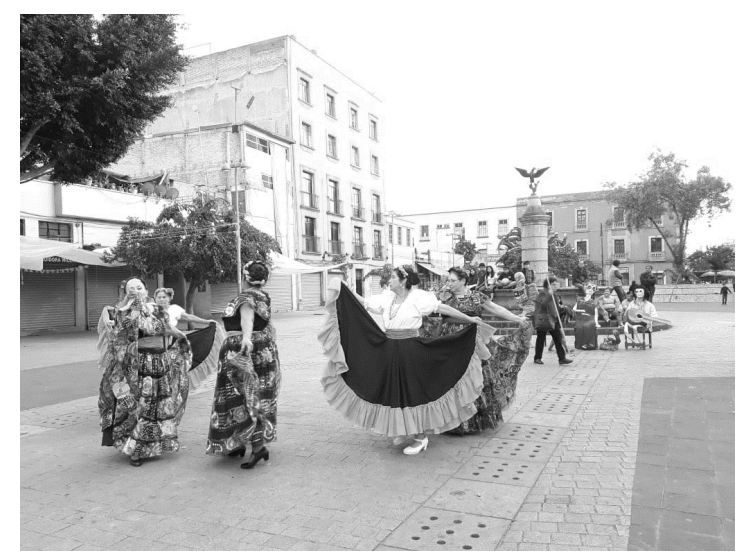

Fig. 6. Plaza "La Aguilita". (Fotografía brigada multidisciplinaria nov. 2018)

Mtro. Manuel López Pliego (especialidad Arqueología y Urbanismo).

Integrantes de la Brigada: Marlene Edith Mendiola Espinoza, Jorge Enrique Arévalo Reyes, Alhelí Callejas Lemus, Ana Paula Zamora Ruíz, Gustavo García Acatitla, Yazmin Sánchez Correa, Irais Alejandra Luis Gallardo, Reynaldo Nájera Román, Iván Alejandro Juárez Morán, Rafael Corona Suchil

En este trabajo se aplicó una metodología tanto cuantitativa como cualitativa con encuestas por muestreo aplicadas a vecinos, visitantes, comerciantes y personas en situación de calle, atraves de cuestionarios estructurados y semiestructurados.

La intención es recuperar la memoria urbana local, por medio de las entrevistas para lograr "una consolidación de la memoria histórica, profundizando en los elementos de la historia local, a través del análisis de documentos diversos, susceptibles de reagrupar, con el fin de generar una imagen al mismo tiempo general y detallada del espacio urbano". (Urrieta 2018:47)

\section{Resultados: Diagnóstico en Plaza Aguilita}

En el entorno de la plaza se ubican 306 inmuebles, de los cuales 107 corresponden a Inmuebles habitacionales con comercio en la planta baja $(\mathrm{H}), 193$ a Inmuebles habitacionales con bodegas (HC), 2 corresponden a Inmuebles escolares (E) y 4 a Inmuebles culturales o deportivos (C). En cuanto a Inmuebles 


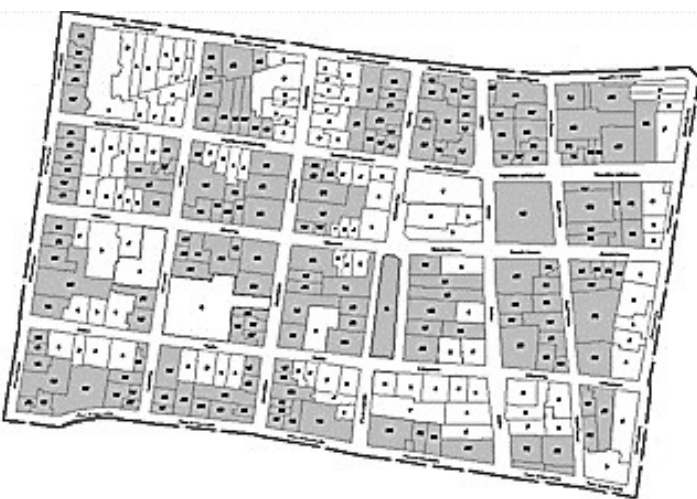

Fig. 7. Inmuebles de uso habitacional (Elaborado por alumnos de topografía de la brigada multidisciplinaria) ${ }^{5}$

escolares se ubicaron 2, uno se encuentra en la esquina de la calle de las Cruces y la calle de Mesones y corresponde a una primaria llamada "Escuela Pública República de El Líbano", el otro está sobre la calle de Regina y es un inmueble propiedad de la Escuela Superior de Ingeniería y Arquitectura (ESIA) unidad Tecamachalco.

En el diagnóstico obtenido se obtienen las siguientes problemáticas:

- La cantidad de perros ensucian la plaza con heces fecales

-La Basura que se genera es excesiva y no se cuenta con botes en la plaza.

- Motos que atraviesan la plaza y son un riesgo para los peatones que transitan la misma

-Inseguridad frecuente con asaltos y droga.

-Personas en situación de calle duermen y habitan la plaza, incluso ha habido muertos en las jardineras.

- La falta de alumbrado público.

-El comercio informal

Para contrarrestar lo anterior la brigada multidisciplinaria propone lo siguiente con la elaboración de un proyecto que contemple:

-Eventos culturales

-Integrar socialmente a las personas en situación de calle

- Arreglar alumbrado público

- Evitar el tránsito de motocicletas

-Instalaciones para hacer ejercicio; juegos

- Poner en funcionamiento de las dos fuentes

- Promover la participación de los jóvenes

- Dotar a la plaza de más árboles

- Poner bancas en la plaza
-Mantenimiento de jardineras

-Mejoramiento de la seguridad pública

\section{Conclusiones: Propuesta de proyecto urbano participativo.}

Al realizar los talleres de participación ciudadana y con la colaboración de las brigadas multidisciplinarias se obtienen diversos discursos de una memoria colectiva que refiere la memoria histórica, plantea las problemáticas existentes, y los vecinos por medio de círculos de reflexión hacen diversas propuestas que son reflejadas en papel y maqueta.

La propuesta última intenta recuperar la memoria histórica y la identidad colectiva de la plaza así como su revalorización, integrando de manera comunitaria a los habitantes en un proyecto urbano arquitectónico en el que sean partícipes tanto de las propuestas como de su ejecución.

Con el apoyo de alumnos, profesores y vecinos se elaboró un proyecto para ser presentado en el Programa de Mejoramiento Barrial y que el gobierno asigne recursos a éste, el cual propone lo siguiente:

Levantar el nivel de las jardineras con taludes a fin de que no duerman los indigentes en las mismas, remarcar el acceso con dos esculturas de un guerrero águila y jaguar, ambos tan representativos de la cultura mexica al hacer alusión al resguardo de la plaza de forma simbólica con el atlanchinolli ${ }^{6}$.

Se propone también el diseño de detalles en el pavimento con significados y simbolismos de acuerdo a la piedra solar o calendario azteca, un paso de agua que refleje al dios azteca Tlaloc simbolizando un paso de purificación. Así como detalles alusivos al corazón de Copil.

Los detalles en el piso se proponen sean realizados por los vecinos en talleres de forma artística por medio de mosaicos donde participen los alumnos de integración plástica asesorando a los vecinos a fin de que al haber realizado ellos estos detalles los hagan suyos en el pavimento y en consecuencia conserven limpia la plaza y la revaloren.

Se propone la participación de Libre Gutiérrez, reconocido muralista de prestigio en la zona, quien fue propuesto por los mismos vecinos para la decoración del larguero lateral 

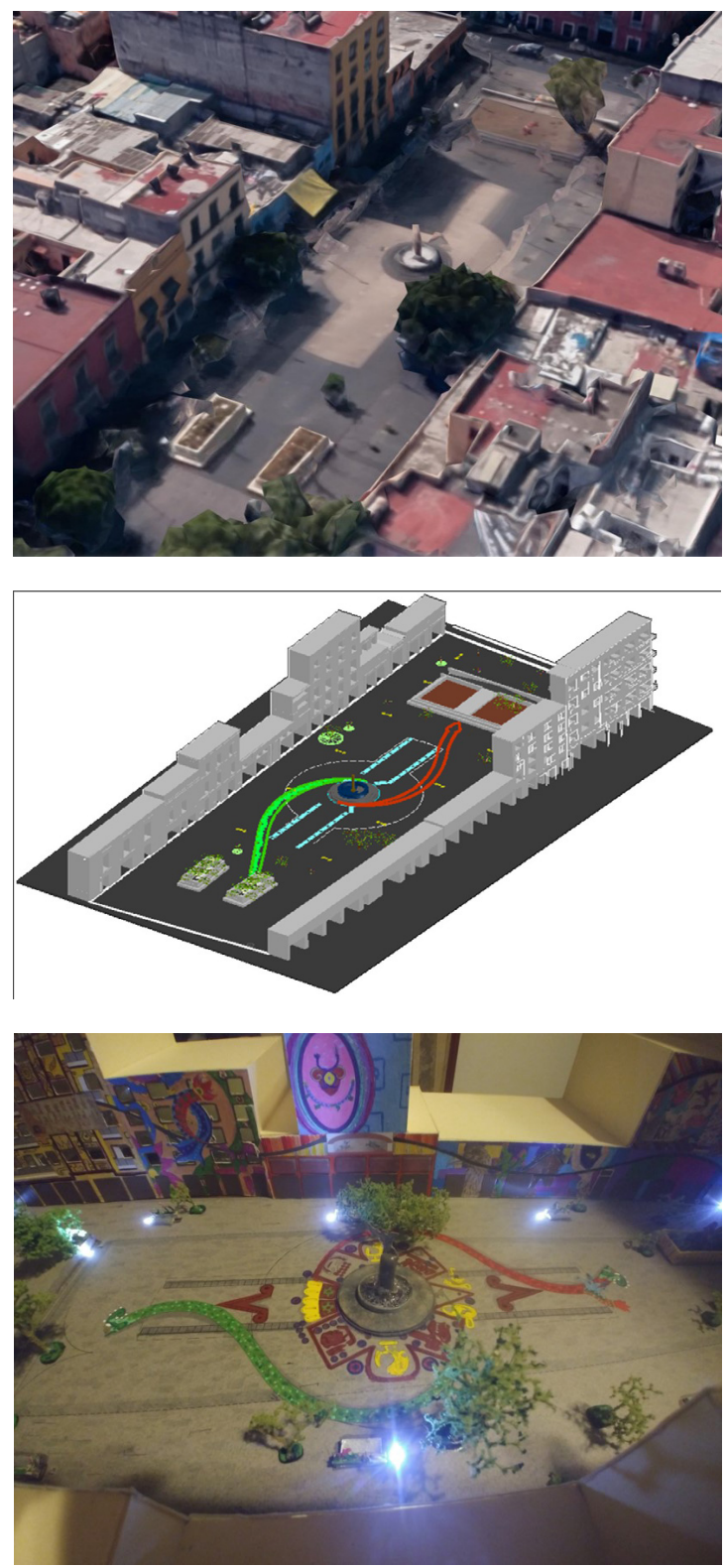

Fig. 8. (arriba) Vista del estado actual de la plaza (Fuente: Brigadas multidisciplinarias 2019)

Fig. 9. (centro) Propuesta del proyecto urbano participativo en Plaza Aguilita (Fuente: Elaboración Maqueta virtual brigadas multidisciplinarias 2019)

Fig. 10. (abajo) Maqueta física del proyecto urbano participativo en Plaza Aguilita (Fuente: Elaboración alumnos del taller de Integración Plástica 2019) ${ }^{7}$

de las fachadas que no son patrimoniales de tal forma que el concepto sea el origen de una cultura, de un barrio, de una nación, y del otro lado las fachadas patrimoniales se restauraran y pintaran.

Se propone por último una velaría en la primera jardinera, respetando los árboles a fin de poder realizar eventos culturales en ese espacio, con el diseño organizado de Arquitectura del Paisaje representado vírgulas y volutas con vegetación que de una imagen de paz y referentes a que la plaza está hablando y contando su historia.

Se sembró un ahuehuete, árbol de agua cuya importancia para los mexicas representaba el sostén de la bóveda celeste.

Las propuestas irán completándose en el transcurso del mismo sin embargo cabe destacar como conclusión final que existía un desanimo por parte de los vecinos, los cuales fueron animándose al ir participando y considerando que eran tomados en consideración para la rehabilitación de su espacio. La Merced es una zona difícil pues hay muchos intereses, sin embargo, la forma de trabajo logró ser unificadora entre los vecinos quienes han ido sumándose, esta forma de trabajo que conlleva una educación ambiental debe considerarse en la intervención actual como parte de una forma innovadora para hacer y desarrollar lo urbano.

Este proyecto representa un inicio para tomar en cuenta a los habitantes en las intervenciones urbanas del espacio público.

\section{Agradecimientos}

Se agradece a la Autoridad del Centro Histórico quien hizo posible la realización de este trabajo y su aporte como organismo gubernamental, también al Instituto Politécnico Nacional en México con la colaboración de las brigadas multidisciplinarias que realizaron su servicio y eran de varias carreras: Topografia, Psicología, Arquitectura Ingeniería, y Turismo. Todas las anteriores colaborando con el Taller de Ciudad y Cultura del Programa de Maestría en Ciencias en Arquitectura y Urbanismo ESIA Tecamachalco.

\section{Notas}

1 Atribuido al cartógrafo Alonso de Santa Cruz. Por el formato de códice que presenta se cree que hubo intervención de manos indígenas en su elaboración Fuente: Méxicomaxico, recuperado el 10 de abril de 2017, en http:// mexicomaxico.org/Tenoch/TenochUpssala. htm Acceso 10 Octubre 2017 
2 La plaza "La aguilita" se encuentra entre la calle Regina - Misioneros y la calle Mesones - Ramón Corona, C.P. 06060, Ciudad de México, CDMX, su nombre oficial es "Plaza Juan José Baz". Cuenta con un perímetro aproximado de 263 metros y una superficie de 3,172 metros cuadrados

3 El hedonismo está relacionado con el precio hedónico, en donde los inmuebles suben de valor en relación a sus atributos en relación al buen vivir.

4 Cocola Agustín Turismo y Gentrificación https://agustincocolagant.net/turismo-ygentrificacion/ Acceso 20 de Octubre de 2018

5 Iván Alejandro Juárez Morán, Rafael Corona Suchil. Noviembre 2018

6 (en náhuatl: atl, agua, tlachinolli, que se quema, 'agua quemada, el agua preciosa, la sangre') es un concepto mexica, basado en el difrasismo de agua versus fuego, dos elementos físicamente opuestos, y que significó para los mexicas la guerra sagrada.

7 Licenciatura de Ingeniería y Arquitectura ESIA Tecamachalco. Instituto Politécnico Nacional

\section{Referencias}

Bauman Zygmunt. (2012) Tiempos líquidos. Vivir en una época de incertidumbre. Ensayo Tus Quets. Editores Barcelona, México.169 págs.

Castillo Berthier (2015) La Merced. El comercio mayorista de alimentos en el Centro Histórico de la Ciudad de México (1900-1960) UNAM México 283 págs.

Cocola Agustín Turismo y Gentrificación https://agustincocolagant.net/turismo-ygentrificacion/ Acceso 20 de Octubre de 2018

González Schmal, Jesús, Lozada Guadalupe (1991) Retratos de lo público. Plazas, parques, calles y jardines. Centro Histórico de la Ciudad de México. Autoridad del Centro Histórico. 159 págs.

Laguna Sánchez, Gerardo (2016). Complejidad y sistemas complejos. Un acercamiento multidimensional. Copit-arXives. Editora 3. 198 págs.

López Morales, Ernesto. "Gentrification de
Loretta Lees, Tom Slater y Elvin Wyly “, en: Revista de Geografía Norte Grande, núm. 44, 2009, pp. 155-158, disponible en http:// www.redalyc.org/pdf/300/30012208010.pdf (Acceso 29 de junio 2014)

Montaner Josep María \& Muxi Zaida. (2017) Arquitectura y política. Ensayos para mundos alternativos. 1 era edición. Editorial Gustavo Gili. 255 págs.

Olivares E., (2017). ¿Dónde se paró el águila? Una historia sobre la fundación de Tenochtitlán. Recuperación: 19/11/2018, de codigoespagueti.com Sitio web: https:// codigoespagueti.com/noticias/cultura/ donde-se-paro-el-aguila/

Sanz Nuria y otros (2018) Sostenibilidad Social y regeneración urbana. El caso del centro histórico. Autoridad del Centro Histórico 351 págs.

Tena Nuñez Ricardo, Urrieta García Salvador (2009) El barrio de la Merced. Estudio para su regeneración integral. Instituto Politécnico Nacional México 390 págs.

Urrieta García Salvador (2018) Espacio Público: de la memoria urbana al proyecto local. Instituto Politécnico Nacional México 221 págs.

Vergara Constela, Carlos. "Gentrificación y renovación urbana. Abordajes conceptuales y expresiones en América Latina", en: Anales de Geografía 2013, vol. 33, núm. 2 219-234. Disponible http://revistas.ucm.es/index.php/ AGUC/article/viewFile/43006/40809 